\title{
Effectiveness of Surgical Treatment of Rockwood Type III Acromioclavicular Joint Dislocation Using Clavicle Hook Plate and Tension Band Wiring: A Comparative Study to Evaluate the Functional and Surgical Outcome
}

\author{
Shrestha $\mathrm{DK}^{1}$, Shrestha $\mathrm{M}^{2}, \mathrm{KC} \mathrm{D}^{1}$, Karki $\mathrm{P}^{1}$, Shrestha $\mathrm{S}^{1}$, Yogi $\mathrm{S}^{1}$
}

\section{ABSTRACT}

Introduction: Acromioclavicular joint dislocation Type III is still controversial for its management, despite of numerous trials and reviews. Aim: To compare and evaluate the functional and surgical outcome of Rockwood Type III acromioclavicular joint dislocation treated surgically with clavicular Hook plate and Tension Band wiring with K-wires. Methods: In a prospective hospital based interventional study comprising of total 22 patients with a mean age of $31.36 \pm 7.53$ years who presented with Rockwood Type III acromioclavicular joint dislocation were carried between January 2018 to December 2019. They were graded according to Rockwood et al. classification. All 22 patients underwent open reduction and internal fixation. These patients were divided into two groups according to operative procedure; of which 11 patients were treated with clavicular hook plate (CHP) and rest 11 were treated with tension band wiring with K-wires (TBW). Descriptive comparison was tabulated during pre-operative, intra-operative and post-operative periods. The Constant-Murley Shoulder scoring system was applied for evaluating the results. Results: The mean follow up period was 7.6 months. The clavicular hook plate was removed at 10 months in one patient due to severe pain and limited range of motion, and removal of Tension Band wiring with K-wires were done in two patients due to wound dehiscence and Kirschner wire back out at 5 and 6 months. The mean Constant- Murley shoulder score was 82.6 ( $\min .70 \& \max .93)$ in clavicular hook plate and 74.72 ( $\min 68$ \& max. 84) in Tension band wiring with K-wires which found to be significantly difference in mean scoring between two groups. Conclusion: Patients treated with Clavicular Hook Plate for Rockwood Type III acromioclavicular joint dislocation had a very good functional and surgical outcome over Tension Band wiring with K-wires.

\section{Keywords: Acromioclavicular joint, Clavicular hook plate (CHP), Constant Murley score, Tension band wiring (TBW)}

\section{Authors:}

1. Dr. Dinesh Kumar Shrestha

2. Dr. Merina Shrestha

3. Dr. Dipendra KC

4. Dr. Prateek Karki

5. Dr. Sabin Shrestha

6. Dr. Sushil Yogi

${ }^{1}$ Department of Orthopedics, Nepalgunj Medical College and Teaching Hospital, Kohalpur, Banke

${ }^{2}$ Department of Community Medicine, Nepalgunj Medical College and Teaching Hospital, Kohalpur, Banke

\section{Address for Correspondence:}

\author{
Dr. Dinesh Kumar Shrestha \\ Associate Professor \\ Department of Orthopedics \\ Nepalgunj Medical College and Teaching Hospital \\ Kohalpur, Banke, Nepal \\ Email: dr_dineshstha@yahoo.com
}

\section{INTRODUCTION}

The Acromioclavicular joint dislocation were also a concerned back to the time of Hippocrates (460-377 BC) and Galen (129199 AD). ${ }^{1}$ Acromioclavicular joint dislocations are increasing in incidence constituting approximately $9-12 \%$ of all shoulder injuries. $^{2,3}$ The effectiveness of surgical management for Acromioclavicular joint dislocation is still controversial despite of numerous trials and reviews. These injuries often occur in and around third decade of life due to fall from a height, fall on an outstretched arm and contact sports injuries, males are predominantly affected with a male: female ratio of $5: 1{ }^{4}$

In acromioclavicular joint dislocation, Rockwood classification is the widely used. It classifies the Acromioclavicular joint dislocation into six types. ${ }^{5}$ Type I, II, III are more frequent and type IV, V and VI are rarer. In type I, Acromioclavicular ligament is strained, in type II acromioclavicular joint is disrupted and Coracoclavicular ligament is strained while in type III, Acromioclavicular and Coracoclavicular ligaments both are 
Shrestha et al.: Effectiveness of Surgical Treatment of Rockwood Type III Acromioclavicular Joint Dislocation Using Clavicle Hook Plate and Tension Band Wiring: A Comparative Study to Evaluate the Functional and Surgical Outcome

disrupted, in type IV distal, clavicle is positioned posterior to acromion process, in type $\mathrm{V}$, there is a gross superior dislocation of the acromioclavicular joint with ruptured Acromioclavicular and Coracoclavicular ligaments and joint capsule and in type $\mathrm{VI}$, distal clavicle positioned inferior to coracoid process. ${ }^{6}$

Type I and II are both are managed conservatively ${ }^{7}$, type IV-VI are preferred for surgery ${ }^{8}$ and type III are variably treated. The best treatment for Rockwood Type III acromioclavicular joint dislocation is still unclear and controversial. The hardware used in this study was3.5 mm Clavicular Hook plate and Tension Band Wiring with $\mathrm{K}$-wires. The clavicular hook plate is a metallic device that keeps the acromioclavicular joint in a reduced position by hooking its tip under the acromion making a tunnel and fixing it to the clavicle with screws. ${ }^{9}$ Similarly, Tension Band Wiring, a fixation method done with two Kirschner wires of $2.0 \mathrm{~mm}$ which was introduced through lateral end of acromion process after acromioclavicular joint reduction and supplemented by circlage wire of $18 \mathrm{G} .{ }^{10}$ The best treatment for Rockwood Type III acromioclavicular joint dislocation is still unclear and controversial. Some authors obtained good to excellent results performing non-surgical management of the patients with type III dislocations. ${ }^{11}$ While others reported persistent pain and other post up complications associated with follow up evaluations. ${ }^{12,13}$

However, surgical intervention is better choice to improve functional outcome of type III Acromioclavicular injuries in young and active patients of specific age group of population who need quick recovery to return back in their daily work activities in time. ${ }^{14}$

The hypothesis of this study reflects the effectiveness of surgical procedure using $\mathrm{CHW}$ method is better than TBW method in comparison of its surgical and functional outcome. This study aimed to compare pre-operative, intra operative and post-operative interventional evaluations of type III ACJ dislocations with their follow ups within six and half month of duration. None of such study conducted in mid-western and far western of Nepal, it is likely to enable the surgeons to prefer such management in terms of stable and rigid fixation, better functional outcome and less time consuming approach for the management of poor patients.

\section{METHODS}

This was a prospective hospital based interventional study carried out from January 2018 - December 2019.The study subjects were total 22 adults ranging from $22-48$ years as nonprobability purposive sampling technique within two years of duration. Two groups were selected on the basis of treatment procedure; one group was comprised of CHP while other group was comprised of TBW. After obtaining ethical permission for the study from the institutional review committee of Nepalgunj Medical College Teaching Hospital, Kohalpur, informed consent was being pertained to maintain the confidentiality of patients.

Patients with unilateral, acute acromioclavicular joint dislocation and close Rockwood Type III with age between twenty two to forty eight years were included in the study whereas open acromioclavicular joint dislocation, associated fractures in scapula, ipsilateral lateral end of clavicle and with other systemic co-morbidities were excluded.

After clinical assessment of the acromioclavicular joint carried out by the Orthopedic surgeon, all the patients were subjected to radiographic evaluation of an anteroposterior view of the shoulder and stress views. ${ }^{15}$ They were treated surgically within 24-72 hours of arrival at the hospital in beach chair position under general anesthesia. Among them 11 patients were treated with clavicular hook plate and 11 patients were treated with Tension Band wiring with K-wires. All patients were followed up for 16 months.

\section{Clavicular Hook Plate}

Clavicular hook plate were performed under general anesthesia in the beach-chair position. A curvilinear incision of $5 \mathrm{~cm}$ was made over the lateral end of clavicle after manually reducing the acromioclavicular joint and exposed both with full thickness soft tissue flap. Any articular cartilage debris in the joint was removed then the acromioclavicular joint was reduced manually and the hook of the plate was inserted beneath the acromion and the proximal end of the plate was screwed into the clavicle by $3.5 \mathrm{~mm}$ screws. Skin was closed in layers after irrigation.

\section{Tension Band Wiring}

Tension band wiring was also performed under general anesthesia in the beach-chair position. A curvilinear incision was made $2 \mathrm{~cm}$ behind the lateral end of clavicle and extended along the axis of clavicle to the acromion. The lateral end of clavicle, acromioclavicular joint and the acromion process were exposed. The displaced clavicle was reduced manually and fixed with two parallel $2.0 \mathrm{~mm}$ stainless steel K-wires using a power drill from the lateral end of the acromion process. The $3.5 \mathrm{~mm}$ cortical screw was inserted after pre drilling with drill bits of $3.2 \mathrm{~mm}$ superiorly and medially over the lateral end of clavicle $2 \mathrm{~cm}$ from the acromioclavicular joint. This fixation was supplemented by stainless steel circlage wire of $18 \mathrm{G}$ making a figure of eight configuration, purchasing cortical screw neck and the lateral end of both the K-wires. The K-wires were bent, cut and its end buried beneath the soft tissue and the skin was closed in layers after irrigation.

Postoperatively all patients were immobilized in arm pouch sling for two weeks. All wounds healed primarily with no wound dehiscence. Active range of motion including shoulder abduction up to $90^{\circ}$ was started immediately as per pain tolerance. After two weeks sutures were removed and they 
Shrestha et al.: Effectiveness of Surgical Treatment of Rockwood Type III Acromioclavicular Joint Dislocation Using Clavicle Hook Plate and Tension Band Wiring: A Comparative Study to Evaluate the Functional and Surgical Outcome

were put on physiotherapy with passive and active-assisted shoulder range of motion. They were followed up for 16 months and the results were assessed at 12 months postsurgery. The clinico-radiological evaluation was done at 1 , 3,6,12 and 16 months. The functional outcome was assessed using Constant-Murley shoulder score. This scoring system consists of four variables that are used to assess the function of the shoulder. The right and left shoulders are assessed separately. The subjective variables are pain (15 points) and activities of daily living (20 points) which gives a total of 35 points. The objective variables are range of motion (40 points) and strength (25 points) which gives a total of 65 points. ${ }^{16,17,18}$

The results of two groups were compared on all study variables to determine whether there was any difference between two surgical procedures. All the relevant information was entered into Microsoft excel, statistical package for social services (SPSS) version 20 and data was analyzed by using statistical tools; frequency, standard deviation, one sample T test and Pearson's correlation coefficient test with statistically significance value less than 0.05 .

\section{RESULTS}

\begin{tabular}{lcc|}
\hline Variables & CHP (f) & TBW(f) \\
\hline Mode of Injury & & \\
\hline Fall from tree & 5 & 4 \\
\hline Fall from cliff & 5 & 1 \\
\hline RTA & 1 & 4 \\
\hline Sports Injury & 0 & 2 \\
\hline Site of Injury & & \\
\hline Right & 10 & 11 \\
\hline Left & 1 & 0
\end{tabular}

Table I. Frequency distribution of pre-operative status between two groups. ( $N=22)$

Mean age of CHP group was 31.45 years and TBW group was 31.27 years. The mechanism of injury included total number of fall from tree in 10 (45.45\%), fall from cliff in $6(27.27 \%)$, road traffic accident in $4(18.18 \%)$ and due to contact sport injury in 2 (9.09\%) patients. In clavicular hook plate (CHP) group consisted of 10 male and one female patient had ten right sided dislocations and one left sided dislocation. However, patients in the tension band wiring (TBW) group consisted of all 11 male had right sided dislocations.

\begin{tabular}{|c|c|c|c|c|c|c|c|c|}
\hline \multirow[t]{2}{*}{ Variables } & \multicolumn{4}{|c|}{ CHP } & \multicolumn{4}{|c|}{ TBW } \\
\hline & $\mathbf{N}$ & Mean & $\begin{array}{c}\text { Std. } \\
\text { Deviation }\end{array}$ & $t$ & $\mathbf{N}$ & Mean & $\begin{array}{c}\text { Std. } \\
\text { Deviation }\end{array}$ & $\mathbf{t}$ \\
\hline Age & 11 & 31.45 & \pm 6.99 & 14.92 & 11 & 31.27 & \pm 7.53 & 13.76 \\
\hline $\begin{array}{c}\text { Duration of } \\
\text { Surgery (mins) }\end{array}$ & 11 & 50.27 & \pm 16.48 & 10.11 & 11 & 70.00 & \pm 15.00 & 15.47 \\
\hline $\begin{array}{l}\text { Total amount of } \\
\text { blood loss (ml) }\end{array}$ & 11 & 150 & \pm 45.82 & 10.85 & 11 & 191 & \pm 45.78 & 13.89 \\
\hline
\end{tabular}

Table II : Comparison of intra operative status between two groups using one sample T-test $(\mathrm{N}=\mathbf{2 2})$
Table II showed mean blood loss in the patients in CHP group and TBW group were $150 \mathrm{ml}$ with SD \pm 45.82 and $190 \mathrm{ml}$ with SD \pm 45.78 respectively which found to be statistically significant difference between mean blood loss of CHP and TBW group ( $P$ $\leq 0.001$ ). Similarly, mean duration of surgery of CHP group and TBW group were $50.27 \mathrm{~min}$. and $70.00 \mathrm{~min}$. respectively also showed significant results between two groups. ( $P \leq 0.001)$
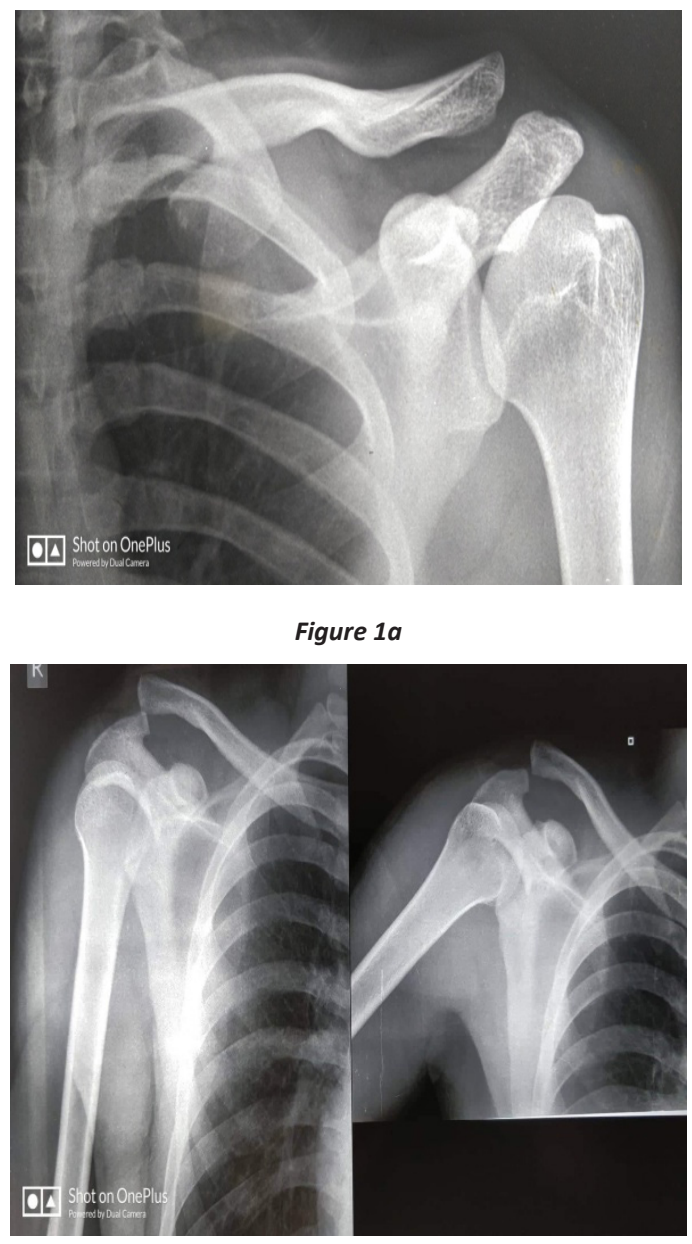

Figure $1 b$

Figure 1 : Pre-operative x-rays for CHP group (Figure 1a) and TBW group (Figure1b)

As per table III, this study encountered only one patient in CHP group, had severe pain and limited range of motion with good Constant-Murley score of 70 at 10 month. Two out of 11 patients had to remove the tension band wiring due to wound dehiscence and K-wire back out at 5 and 6 months whose Constant-Murley score was 68 and 72 respectively. All the patients were followed up for 16 months post operatively. The internal fixation device was removed within 5 to 12 months depending on the patient's status of recovery. The mean of Constant Murley scores were 82.63 with SD \pm 7.54 in CHP group and 74.72 with SD \pm 4.81 in TBW group. Statistically significant results were obtained while comparing the mean scoring of functional outcome in between subjects of two groups ( $p=<$ 0.001). 
Shrestha et al.: Effectiveness of Surgical Treatment of Rockwood Type III Acromioclavicular Joint Dislocation Using Clavicle Hook Plate and Tension Band Wiring: A Comparative Study to Evaluate the Functional and Surgical Outcome

\begin{tabular}{|ccccccccc|}
\hline Groups & \multicolumn{4}{c}{ Post up complications } & & \multicolumn{3}{c|}{ Constant Murley Score } \\
\hline $\begin{array}{c}\text { Types of } \\
\text { Surgery }\end{array}$ & $\begin{array}{c}\text { Severe } \\
\text { pain }\end{array}$ & $\begin{array}{c}\text { Limited } \\
\text { ROM }\end{array}$ & $\begin{array}{c}\text { Wound } \\
\text { dehiscence }\end{array}$ & $\begin{array}{c}\text { K wire } \\
\text { back out }\end{array}$ & None & Mean \pm SD & P \\
CHP & 1 & 1 & 0 & 0 & 9 & $82.63 \pm 7.54$ & 0.001 \\
TBW & 0 & 0 & 2 & 2 & 7 & $74.72 \pm 4.81$ & 0.001 \\
\hline
\end{tabular}

Table III : Frequency distribution of post operative complication and comparision of mean of functional scoring in two groups using one sample $T$-test $(\mathrm{N}=22)$

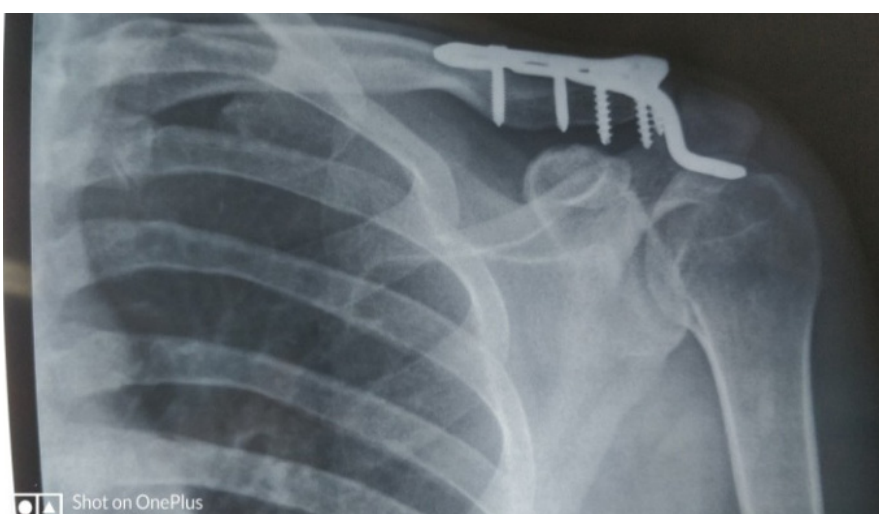

Figure $2 a$

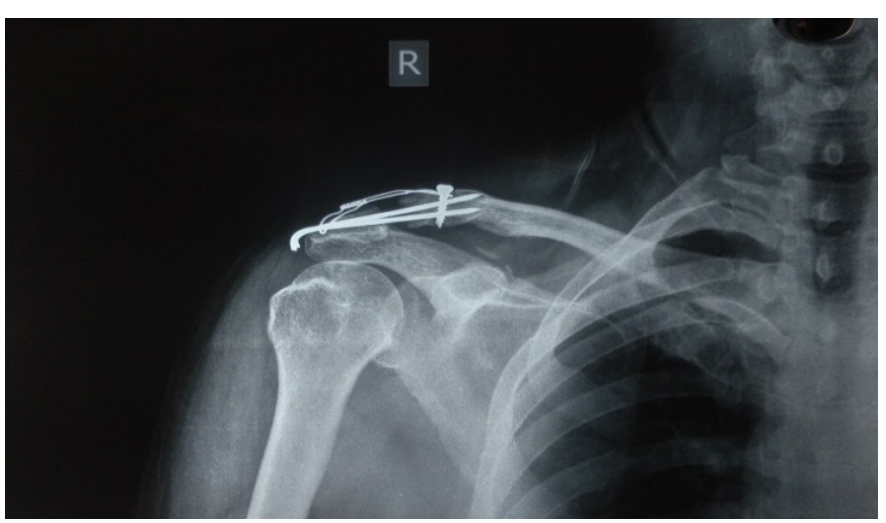

Figure $2 b$

Figure 2 : Post-operative $x$-rays showing CHP figure (2a) and TBW figure (2b)

As shown in table no. IV and fig. no. 3 , the subjects of CHP group had maximum blood loss of $220 \mathrm{ml}$ with duration of surgery ranging min. 30 minutes to max. 90 minutes while in subjects of TBW group the maximum blood loss was $250 \mathrm{ml}$ with duration of surgery ranging from 50 minutes to 100 minutes. The bivariate relation between two dependent variables in subjects of CHP group showed positive and moderate linear relationship to each other $(r=0.47)$ with statistically significant correlation $(p \leq 0.05)$ in total population. In contrast, the subjects of TBW group had no linear relationship between blood loss and duration of surgery $(r=0.0)$ and have found to be statistically insignificant correlation $(p=0.94)$ in total population.

\begin{tabular}{|c|c|c|c|c|c|}
\hline & $N(f)$ & (Min- Max) & $\begin{array}{c}\text { Mean } \pm \\
\text { SD }\end{array}$ & $\begin{array}{c}\text { Correlation } \\
\text { Mean } \pm \text { SD } \\
\text { Coefficient ( } r \text { ) }\end{array}$ & $\begin{array}{c}\text { sig. } \\
\text { (2-tailed) }\end{array}$ \\
\hline $\begin{array}{l}\text { CHP } \\
\text { Duration } \\
\text { of Surgery } \\
\text { (mins.) }\end{array}$ & 11 & $\begin{array}{l}30.00- \\
90.00\end{array}$ & $\begin{array}{c}50.2 \pm \\
16.4\end{array}$ & 0.47 & 0.020 \\
\hline Blood loss & 11 & $\begin{array}{l}90.00- \\
220.00\end{array}$ & $\begin{array}{c}150 \pm \\
45.8\end{array}$ & & \\
\hline $\begin{array}{l}\text { TBW } \\
\text { Duration } \\
\text { of Surgery } \\
\text { (mins.) }\end{array}$ & 11 & $\begin{array}{l}50.00- \\
100.00\end{array}$ & $\begin{array}{l}70 \pm \\
15.0\end{array}$ & 0.0 & 0.94 \\
\hline Blood loss & 11 & $\begin{array}{l}120.00- \\
250.00\end{array}$ & $\begin{array}{r}191 \\
\pm 45.7\end{array}$ & & \\
\hline
\end{tabular}

Table IV : Comparison of intra operative relation between two groups using Pearson's correlation co-efficient test ( $N=22)$

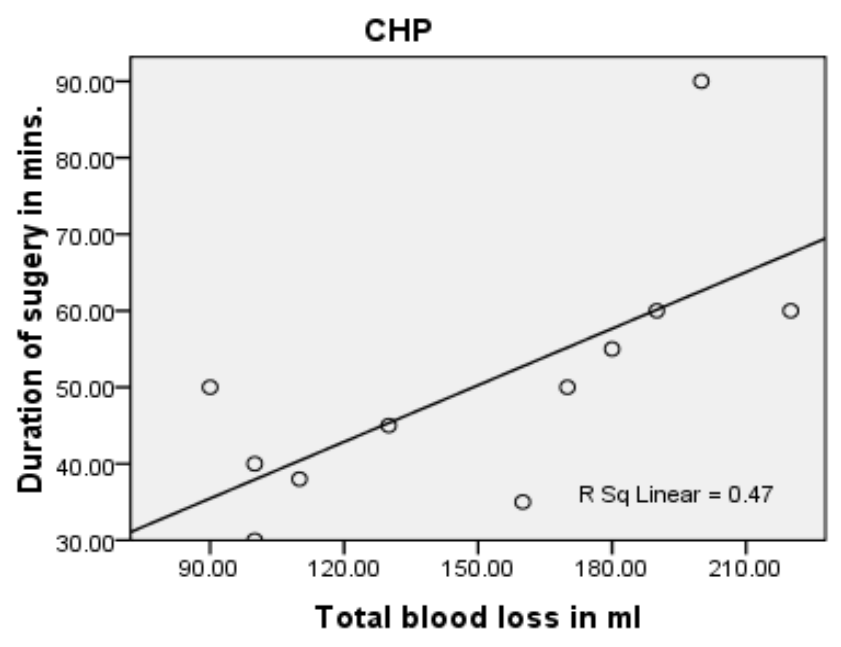

Figure $3 a$

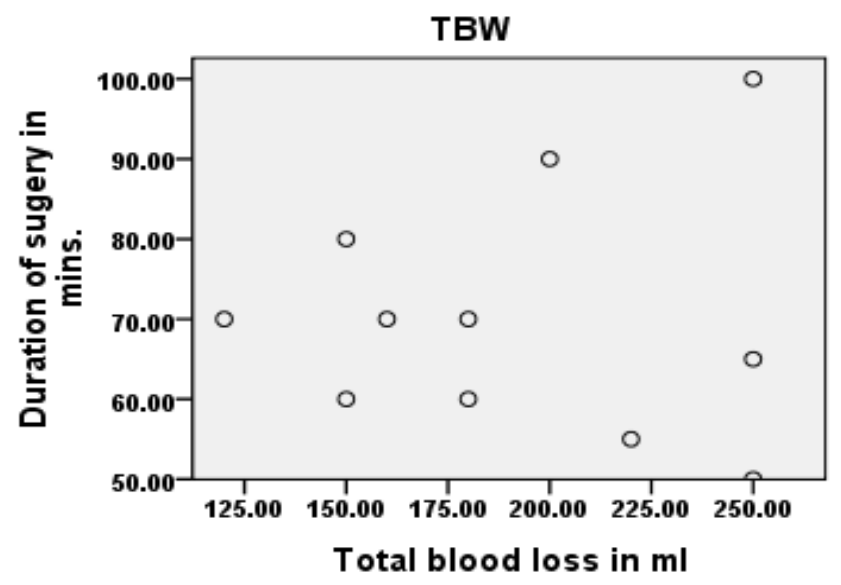

Figure $3 b$

Figure 3 : Scatter plot diagram of bivariate correlation co-efficient of mean blood loss and duration of surgery between two group showing positive correlation in Figure $3 a$ and no correlation in Figure $3 b$. 

Tension Band Wiring: A Comparative Study to Evaluate the Functional and Surgical Outcome

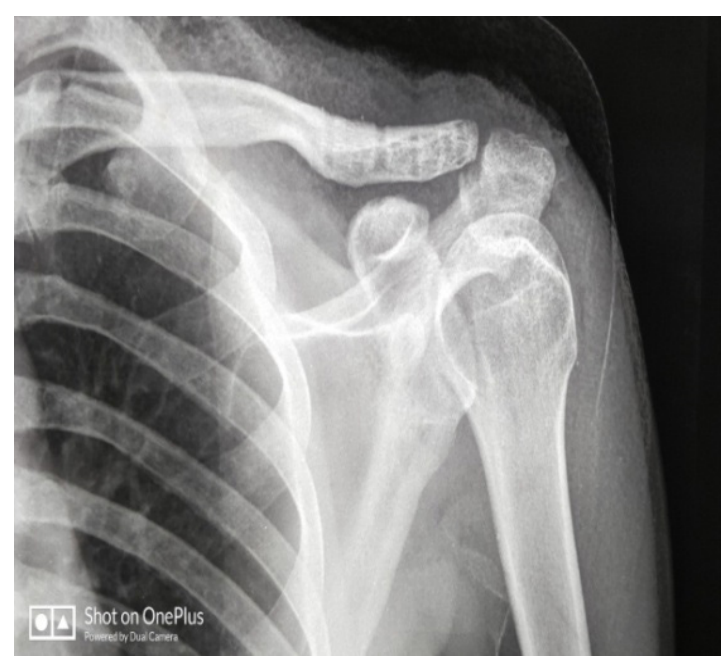

Figure $4 a$

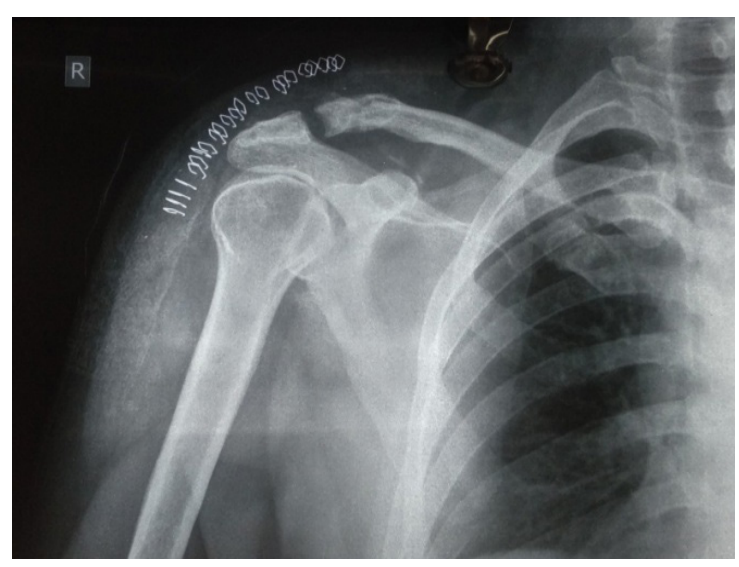

Figure $4 b$

Figure 4 : Follow up $x$-rays showing status of healing process after removal of implant for CHP (4a) and TBW (4b) group.

\section{DISCUSSION}

Despite of numerous trials and reviews, there is still no consensus and clear view on ideal device or method for fixation of type III acromioclavicular joint dislocation. However, there are both conservative as well as operative evidences, but most of the patients treated with conservative method had unsatisfactory results, with residual pain during shoulder movement, paranesthesia, loss of strength and fatigue with overhead activities and cosmetic concerns. ${ }^{19,20}$ Hence operative methods are being done quite frequently such as clavicular hook plate, Fixation with K-wires, Tension band wiring, Fixation with double button technique, reconstruction of the Coracoclavicular ligaments with auto graft or allograft tendon, Bosworth screw fixation and many more. ${ }^{21}$ In this study we have compared the surgical and functional outcome of clavicular hook plate and tension band wiring done in Rockwood Type III acromioclavicular joint dislocation. In both the groups, mean age is very similar; 31.45 years in clavicular hook plate and 31.27 years in tension band wiring with $\mathrm{K}$-wires.
In first group the hook of a clavicular hook plate is placed under the acromion and act as a leverage to push the plate downward, maintaining a proper anatomical alignment of lateral end of clavicle with that of acromion, providing a stable environment for the healing of ligaments and joint capsules. ${ }^{22}$ This technique is simple, yet can be performed with only basic instruments by every surgeon. However the presence of hook underneath the sub acromion space and may have adverse effects and easily leads to pain and stiffness of shoulder, which subsides easily by the time. ${ }^{23}$ This study encountered only one patient with the above mentioned adverse effects which was addressed by removing the plate at 10 months. He had good Constant-Murley shoulder score of 70. The mean difference of functional score had (82.63 with SD \pm 7.84) in CHP group and (74.72 with SD \pm 4.81 ) in TBW group, which revealed significant and improved outcome at $12^{\text {th }}$ week of follow up subsequently using clavicular hook plate method than using tension band wire method. Study done in military personnel by Narinder kumara had also shown similar results. ${ }^{24}$

Gohring et al. has shown higher risk of complications for tension band wiring (43\%) while treating acromioclavicular joint dislocation. ${ }^{25}$ This study has confirmed the same in comparison to CHP. During early postoperative complication, two cases from TBW group had wound dehiscence and kwire back out which was addressed by removing the tension band wiring at 5 and 6 months though their Constant-Murley shoulder score were 68 and 72 respectively.

In this study, visual estimation method for blood loss measurement is applied though it provides least accuracy but it is commonly used. ${ }^{26}$ Mean blood loss was $150 \mathrm{ml}$ in CHP group whereas $191 \mathrm{ml}$ in TBW with K-wires. The surgical time is measured by using a stop watch. It starts immediately from skin incision to the last knot of skin closure. The duration of surgery for clavicular hook plate group was significantly shorter by mean 50.27 min. probably due to easy procedure, single plate device with good fixation than in TBW group where wound incision is larger with uses of many hard wares. This study has shown significant and moderate positive correlation between duration of surgery and blood loss in CHP group than in TBW group. As a result, shorter the procedure, lesser the blood loss exist in CHP group. Thus, the hypothesis formulated in this study is strongly supported by the concrete evidence based on comparative outcomes of two groups.

The conclusive outcome depends upon the various factors such as the study group, patient activity requirement, surgical expertise, types of fixation and reconstruction, and an environmental factors etc. ${ }^{27}$

\section{LIMITATIONS}

This study had various limitations. The sample size of study was not large enough (twenty two), hence cost effectiveness could 
Shrestha et al.: Effectiveness of Surgical Treatment of Rockwood Type III Acromioclavicular Joint Dislocation Using Clavicle Hook Plate and Tension Band Wiring: A Comparative Study to Evaluate the Functional and Surgical Outcome

not be analyzed due to less study number, Axillary radiographs were not performed for assessing the severity of dislocation and above all, ignorance of the pathology due to poor socioeconomic and poor intellectual status of the people. However, this study may contribute to national data or reviews for making a common consensus of our country.

\section{CONCLUSION}

The comparative study of CHP and TBW for Type III Acromioclavicular joint dislocation is effective techniques regarding the subjective view; pain and activities of daily living, and radiographic results. However, the objectives ie; shoulder range of motion, Constant Murley Score and degree of strength are better in CHP group. Similarly, shorter the duration of surgery, the lesser the amount of blood loss emphasize on quick recovery and return back to normal activities earlier in case of CHP method is comparatively better than TBW method. So, Patients treated with CHP has a very good functional and surgical outcome over TBW.

\section{REFERENCES}

1. Adams FL. The Genuine Works of Hippocrates. New York: William Wood;1986.

2. Trainer G, Arciero RA, Mazzocca AD. Practical management of grade III acromioclavicular separations. Clin J Sport Med. 2008;18(2):162-166.

3. Motta P, Bruno L, Maderni A, et al. Acromioclavicular motion after surgical reconstruction. Knee Surg Sports Traumatol Arthrosc. 2012;20(6):1012-1018.

4. MacDonald PB, Lapointe P. Acromioclavicular and sternoclavicular joint injuries. Orthopedic Clinics of North America. 2008; 39(4):535-545.

5. De Carli A, Lanzetti RM, Ciompi A, Lupariello D, Rota P, Ferretti $A$, et al. Acromioclavicular third degree dislocation: surgical treatment in acute cases. J OrthopSurg Res. 2015 Jan;10(13)1341-1413.

6. Gorbaty, J. D., et al. (2017). "Classifications in Brief: Rockwood Classification of Acromioclavicular Joint Separations." Clinical Orthopaedics and Related Research ${ }^{\circledR}$ 475(1): 283-287.

7. Rolf O, Hann von Weyhern A, Ewers A, Boehm TD, Gohlke F. Acromioclavicular dislocation Rockwood III-V: results of early versus delayed surgical treatment. Arch Orthop Trauma Surg. 2008;128:1153-1157.

8. Post M. Current concepts in the diagnosis and management of acromioclavicular dislocations. ClinOrthopRelat Res. 1985;200(200):234-247.

9. Bhandari M.Evidence-Based Orthopaedics.Wiley-Blackwell;2012

10. Canadian Orthopaedic Trauma Society. Multicenter Randomized Clinical Trial of Nonoperative Versus Operative Treatment of Acute Acromio-Clavicular Joint Dislocation. J Orthop Trauma. 2015; (29):479-487.
11. Taft TN, Wilson FC, Oglesby JW. Dislocation of the acromioclavicular joint. An end-result study. J Bone Joint Surg Am. 1987;69(7):1045-51

12. Mouhsine E, Garofalo R, Crevoisier X, Farron A. Grade I and II acromioclavicular dislocations: results of conservative treatment. J Shoulder Elbow Surg. 2003;12(6):599-602.

13. Wojtys EM, Nelson G. Conservative treatment of Grade III acromioclavicular dislocations. ClinOrthopRelat Res. 1991;268:112-9.

14. Lizaur A, Sanz-Reig J, Gonzalez-Parreño S. Long-term results of the surgical treatment of type III acromioclavicular dislocations: an update of a previous report. J Bone Joint Surg (Br) 2011;93(8):1088-92.

15. F. F. Adam and O. Farouk,"Surgical treatment of chronic complete acromioclavicular dislocation," International Orthopaedics. 2004;28(2)119-122.

16. Constant C R, Murley A H G. A clinical method of functionalassessment of the shoulder. Clinical Orthopedics and Related Research. 1987;(214):160-164.

17. Constant C R. Assessment of the shoulder. In:Watson M. Surgicaldisorders of the shoulder. Churchill Livingstone, New York: 1991. 39-45

18. Constant C R. Constant Scoring Technique for Shoulder Function. SECEC information; 1991. Nr 3

19. J. H. Bargren, S. Erlanger, and H. M. Dick, "Biomechanics and comparison of two operative methods of treatment of complete acromioclavicular separation," Clinical Orthopaedics and Related Research. 1978;(130):267-272.

20. L. Stam and I. Dawson, "Complete acromioclavicular dislocations: treatment with a Dacron ligament," Injury. 1991;22(3):173-176. 1991.

21. KorstenKoos, Gunning Amy C, Leenen Luke P H. Operative or conservative treatment in patients with Rockwood type III acromioclavicular dislocation: a systematic review and update of current literature. IntOrthop. 2014;38(4):831-838.

22. Dou $Q$, Ren X. Clinical therapeutic effects of AO/ASIF clavicle hook plate on distal clavicle fractures and acromioclavicular joint dislocations. Pak J Med Sci. 2014;30(4):868-871.

23. Chiang CL, Yang SW, Tsai SW, Kuen-Huang Chen C. Acromion osteolysis and fracture after hook plate fixation for acromioclavicular joint dislocation: a case report. J Shoulder Elbow Surg. 2010 jun;19(4):13-15.

24. Kumar N., Sharma V. Hook plate fixation for acute acromioclavicular dislocations without coracoclavicular ligament reconstruction: a functional outcome study in military personnel. Stratregies Trauma Limb Reconstr.2015 Aug;10(2):79-85.

25. Gohring U., Matusewicz A., Friedl W., Ruf W. Treatment results after various surgical methods in the management of acromioclavicular disruption. Chirurg. 1993;64(7):565-571.

26. Schorn MN. Measurement of blood loss: review of the literature. J Midwifery Womens Health. 2010;55(1):20-7.

27. Jambukeswaran P. S. T, Senthilnathan A., Prabhakar R. The Functional Outcome of Management of Acute Acromioclavicular Joint Disruption Using Tension Band Wiring. JMSCR. 2016 Nov;4:11. 